\title{
Smart Irrigation Prediction using Artificial Neural Network (ANN) with Evapotranspiration Rate Equations and Internet of Things (IoT) for Paddy Field
}

\author{
Muhammad Zahid bin Hilmi, Toni Anwar, Dayang Rohaya Awang Rambli
}

\begin{abstract}
It is estimated that by 2050, the world's population will increase to 10 billion people and water scarcity is going to be a major problem due to an increase number of populations with limited water resources. One of the ways to tackle this problem is by having a precision irrigation which is by estimating the crops water need in which it can improve water utilization. This research is very suitable to be implemented for paddy since paddy consumed a lot of water compared to other types of crops. In order to be able to do it, ANN and Evapotranspiration Rate equation will be used to develop a prediction model to estimate water lost. The prediction model in theory will analyze the historical data and compared it with current data collected in the field and predict water needs based on the output concluded. IoT will act as monitoring and controlling platform for irrigation by automating the irrigation which in result, better water utilization. Prediction model and IoT combination proved that better water utilization can be achieved. The targeted result will be to achieve better water utilization using prediction model and IoT.

Keywords: Artificial Neural Network, Internet of Things, Evapotranspiration Rate, Irrigation, Paddy
\end{abstract}

\section{INTRODUCTION}

Agriculture is an important sector in the world especially for developing countries such as Malaysia itself and other neighbouring country around South East Asia (SEA) such as Indonesia and Thailand [1], [2]. Most farmers in developing countries are economically dependent on agriculture as their source of income [3].

According to the United Nation (UN), by 2050, it is estimated that the number of populations will increase up to 10 billion people. This will have a big impact on the agricultural sector as this sector need to step up their production. This sector needs to increase by $70 \%$ from its

Revised Manuscript Received on March 16, 2020.

* Correspondence Author

Muhammad Zahid bin Hilmi*, CIS Department, Universiti Teknologi PETRONAS, Tronoh, Malaysia. Email: zahid_19000298@utp.edu.my

Toni Anwar, CIS Department, Universiti Teknologi PETRONAS, Tronoh, Malaysia. Email: toni.anwar@utp.edu.my

Dayang Rohaya Awang Rambli, CIS Department, Universiti Teknologi PETRONAS, Tronoh, Malaysia. Email: dayangrohaya.ar@utp.edu.my

(C) The Authors. Published by Blue Eyes Intelligence Engineering and Sciences Publication (BEIESP). This is an open access article under the CC BY-NC-ND license (http://creativecommons.org/licenses/by-nc-nd/4.0/) current state so that it is enough to feed to world. This makes things worst because with the current crop production trend, it might not be able to supply the demand as stated by 2018 Global Agricultural Productivity (GAP) [4], [5]. According to 2018 GAP Report, today's consumers expected more foods than previous generation due to variety of choices and preferences available to be purchased and they now do consider the food values such as quality. If not tackled, the Sustainable Development Goals initiative number 2 (refer to Fig. 1) which is Zero Hunger by 2050 especially for small-scale farmers in low-income countries might not be achieved.

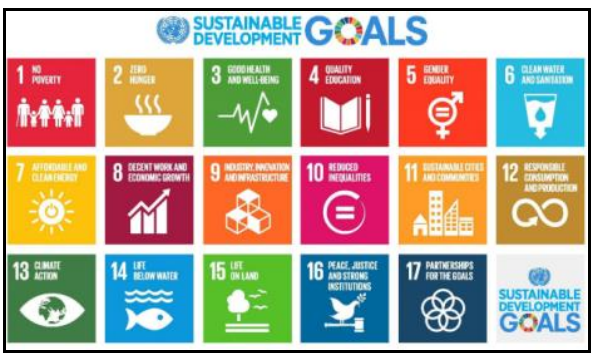

Fig. 1: Sustainable Development Goals https://www.un.org/development/desa/disabilities/envision2 $\underline{030 . h t m l}$

According to Food and Agriculture Organization of the United Nation, agriculture consume on average $70 \%$ of world freshwater and in some countries, up to at $90 \%$ water usage [6], [7]. This mean that water is a critical resource for agriculture purposes which act as main sources for the farmers to grow crops and being mentioned by Forbes too [8]. Without water, the farmers cannot grow any crops, thus affecting their source of income.

This research will focus on paddy irrigation as the case study since in "Chapter 2: Crop Water Needs" by FAO mentioned that even though sugarcane utilize the highest amount of water, but then, sugarcane is not a staple food as compared to paddy which are consumed by majority of world population [9]. Paddy do need a lot of water to grow, so the needs to manage its water needs is needed. So, the method is by estimating its water lost using evapotranspiration rate equations such as Penman-Monteith, Hargreaves and Turc with the use of prediction models such as Long-Short Term Memory,

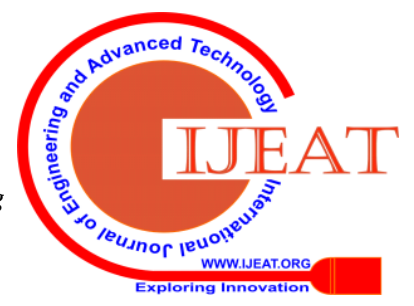




\section{Smart Irrigation Prediction using Artificial Neural Network (ANN) with Evapotranspiration Rate Equations and Internet of Things (IoT) for Paddy Field}

Feed Forward Neural Network and Multivariate Linear Regression in order to fully utilize water use by only watering the paddy when needed.

\section{A. Problem Statements}

Based on previous literature that had been reviewed, there are several problems that have been identified:

1) There is a need for irrigation prediction since it is the most important aspect in agriculture because plant need water to grow and without water, agriculture is not possible.

2) There is a need to improve prediction accuracy for irrigation to improve water utilization to the maximum.

3) Paddy's irrigation needs to be optimized due to its irrigation technique which is not possible to change but rather its way of supplying water by accurately predicting irrigation when needed.

\section{B. Research Questions}

There are several questions that will be answered in this research in order to tackle the irrigation problems:

1) Can prediction models be used to predict water lost estimation?

2) How accurate the water lost estimation by using predictions models and evapotranspiration rate equations?

3) Which prediction models with evapotranspiration rate equations combination offer better water lost estimation?

\section{Research Objectives}

Based on the problem statements, the research objectives will be:

1) To study which prediction models and which evapotranspiration rate equations combination that has highest evapotranspiration rate estimation.

2) To estimate evapotranspiration rate using 3 prediction models with 3 evapotranspiration rate equations combination for highest estimation accuracy.

3) To compare 3 prediction models with 3 evapotranspiration rate equations combinations to find the highest evapotranspiration rate estimation with the nearest accuracy to the observed forecast.

\section{Scopes of Research}

This research will focus on prediction using Artificial Neural Network (ANN) and controlling based on predicted outcome using Internet of Things (IoT) for irrigation of paddy field. With IoT, it also will be used as a monitoring platform to collect data from the sensors placed on the paddy field.

This study will cover:

1) A solution for irrigation using prediction model.

2) This solution will be a combination of ANN and IoT.

3) The solution will be applied for paddy crops in paddy field.

4) The location of the research study will be Parit, Perak, Malaysia.

\section{LITERATURE REVIEW}

\section{A. What is an Irrigation and its Importance for Paddy?}

There are two ways to cultivate the plant/crops according to

Fig. 2: Surface irrigation

https://climatenewsnetwork.net/rice-puddling-raises-methan

2) Sprinkler irrigation

- Water is distributed using water sprinklers into the air to mimic rainfall.

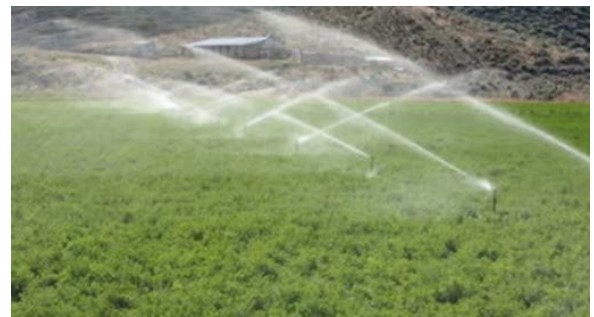

Fig. 3: Sprinkler Irrigation

https://www.indiamart.com/proddetail/sprinkler-irrigation-6 241827048.html

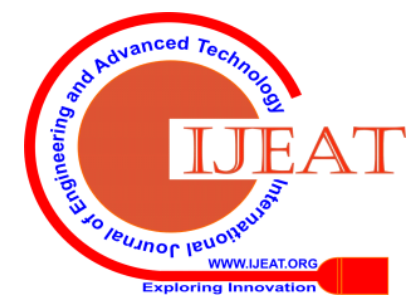


3) Drip/Trickle irrigation

- Water is directly injected or near to the roots.

- The most efficient technique because it reduces evaporation rate.

- The most water saving method.

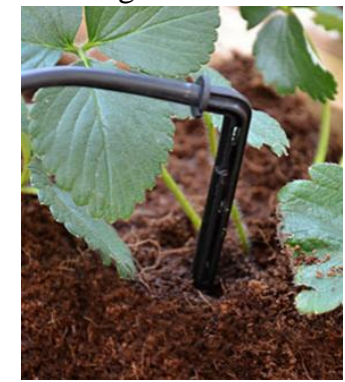

Fig. 4: Drip Irrigation

https://www.burpee.com/gardening-supplies/greenhouse-ac cessories/drip-irrigation-kit-for-palram-greenhouses-prod22 542.html

4) Subsurface irrigation

- Water is distributed just under the soil surface.

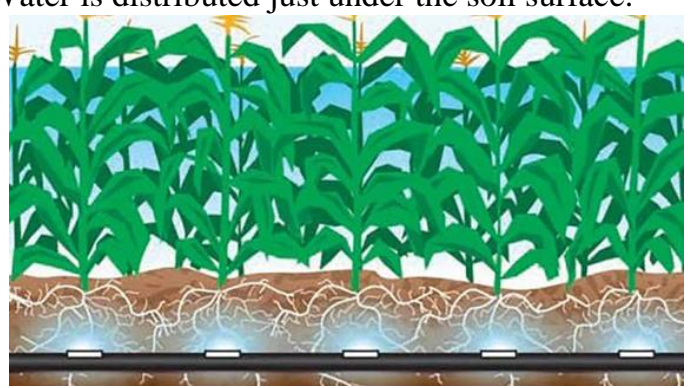

Fig. 5: Subsurface Irrigation

http://aridagriculture.com/2017/09/26/water-conservation-a nd-arid-agriculture/subsurface-irrigation-systems/

Additional irrigation technique according to Centers for Disease Control and Prevention (CDC):

1) Localized irrigation

2) Center pivot irrigation

3) Lateral move irrigation

Irrigation is an important process in agriculture and for paddy, it is crucial to get optimum irrigation since it will affect the growth. According to Facon and Rice Knowledge Bank (RKB), paddy consume about $34 \%$ to $45 \%$ of total water for irrigation [13], [14]. Paddy scientific name is Oryza Sativa is a semiaquatic plant which mean it is a semi submerged plant. It also is very sensitive towards lack or excess of water due to its semiaquatic attributes [14]. According to Integrated Agricultural Development Area (IADA), Rice Knowledge Bank (RKB) and Food and Agricultural Organization (FAO), throughout the whole process from planting until 2 weeks before harvesting, paddy will be partially submerged [14], [15], [16]. Rowshon et al. (2014) explained that, every stage of growth period has different level of water submergent as shown on Fig 6 with water from 60 days and up to 160 days depending on its variety planted [17]. Water is lost nearly half from $3600 \mathrm{~km}^{3}$ due to evaporation and transpiration and with drip irrigation, farmers can have the most reduction of water usage [18].

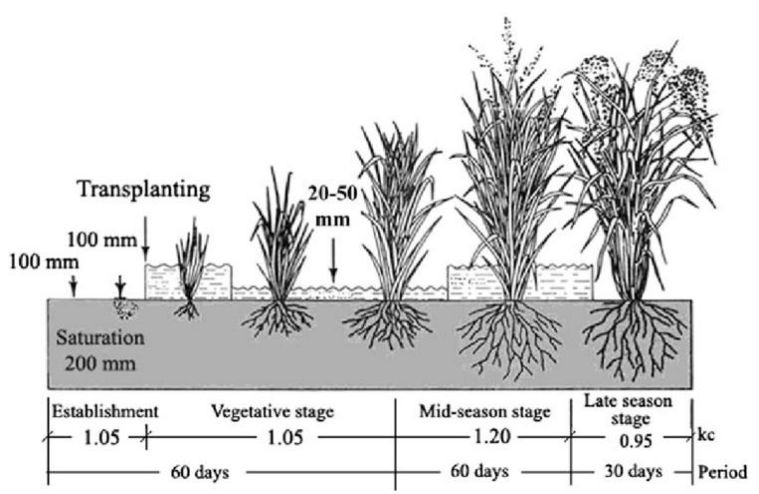

Fig. 6: Growth Period to Water Level Stages

https://www.researchgate.net/publication/257495334_Estim ated_evapotranspiration_of_rice_based_on_pan_evaporatio

n_as_a surrogate to lysimeter_measurement

\section{B. Why paddy need a Smart Irrigation?}

Paddy scientific name is Oryza Sativa is a semiaquatic crop that need constant flow of water throughout the planting process till harvesting process which varies from 60 days and up to 160 days depending on its variety. Paddy is sensitive toward water shortage and need constant water in the field or it will affect the growth which maybe be stunted or even wilt to die thus can affect the yield [19]. On average, one (1) kilogram of paddy will require 500 litres to 1500 litres of waters and some up to 5000 litres of water [19], [20]. Wind speed, air humidity, air temperature, solar radiation and relative humidity can influence evaporation and transpiration rate in which it will translate to the need for extra irrigation which equal to extra water need [16], [21]. Some other factors that influence the need for irrigation are the paddy variety planted, fertilization composition used, regime implemented, pest and disease control needed, soil properties and geography [14], [19]. Rice can be divided into length and shape, texture, colour and aroma. Each of these different serves for different purpose for cooking and also depending on the region. With current irrigation process, it will need to provide the paddy field with $10 \mathrm{~mm}$ of water every day until it is ready to be harvested without considering of all those other factors mentioned in [19], [21]. According to Gulati and Thakur (2018), one third of freshwater was used to irrigate paddy field only from $70 \%$ of the total global freshwater which is not sustainable in a long run [21]. This is due to the population number that is estimated to increase to almost 10 billion by 2050 . With smart irrigation, it can reduce water utilization in which it will directly tackle the irrigation problem by considering all those factors mentioned by Gulati, Thakur and Bouman. As a result, it will assist the farmers in their decision-making process for irrigation. This will indirectly save their time and energy doing irrigation work because it is an intensive labour work due paddy property that is sensitive towards water excess or lost. Drip irrigation is best irrigation technique available due to its technique that directly supply water to the root zone and it is the most water saving technique compared to other irrigation technique according to multiple source such as Centers for Disease Control and Prevention (CDC),

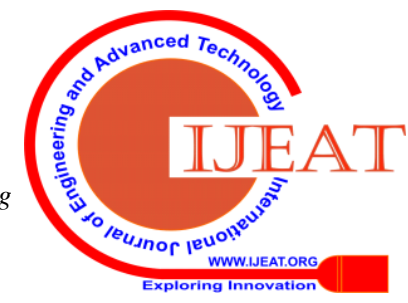




\section{Smart Irrigation Prediction using Artificial Neural Network (ANN) with Evapotranspiration Rate Equations and Internet of Things (IoT) for Paddy Field}

Northeast Region Certified Crop Adviser (NRCCA) and Wikipedia [10], [12], [22].

This technique reduce water lost due to evaporation and transpiration due to its irrigation technique. It also minimized the fertilizer and nutrient loss by using this irrigation technique [22]. But the drawback of this irrigation technique is, it is not suitable for paddy because it promotes weed growth in which it can be avoided by submerging paddy. Due to high capital investment per hectare, drip irrigation technique is not suitable for close growing crops such as rice [23], [24]. In Chapter 7 also mentioned that introducing an unknown method may lead to unexpected complications which in this case monetary loss [24].

\section{Current Irrigation Techniques for Paddy}

Malaysia is blessed because it is situated in monsoon area which mean that Malaysia do get a lot of rainfall which they can use it for irrigation. With a good rainfall, the farmers do not need to do manual irrigation to irrigate their field which is good for them as it is a labour-intensive work [24], [25]. But when there is no rainfall, most farmers do get their water source for irrigation either from water canal, river and underground water or even their water reserves that they collect during rainfall.

As for paddy field, there are currently two irrigation techniques applied:

1) Manual irrigation

2) Alternate Wetting and Drying (AWD)

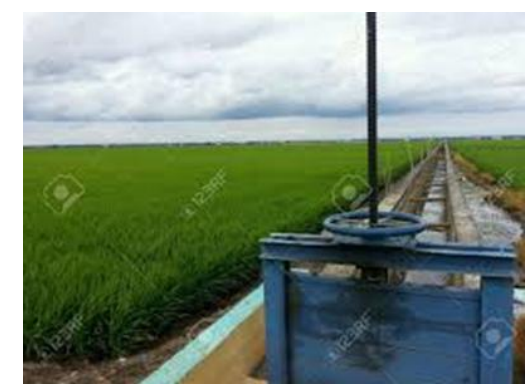

Fig. 7: Water Gate

https://www.123rf.com/photo_23812438_canal-water-gatein-paddy-field.html

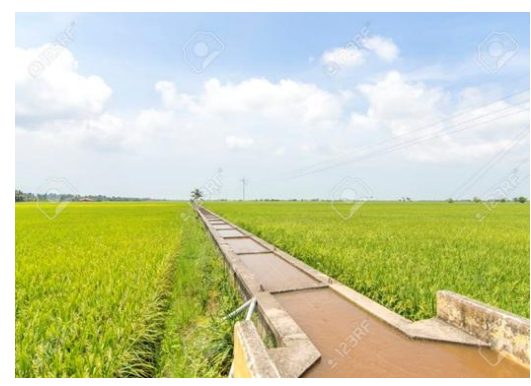

Fig. 8: Water Canal

https://www.123rf.com/photo_39671119_water-canal-for-p addy-rice-field-irrigation-with-blue-skies.html

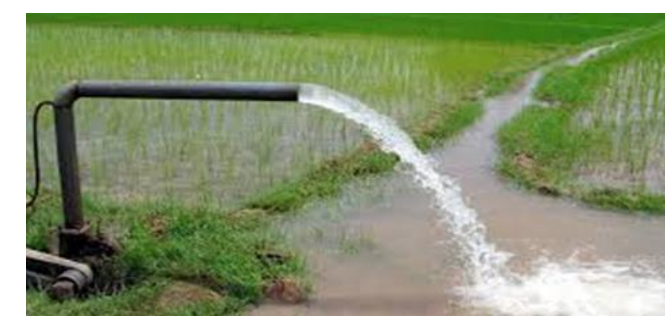

Fig. 9: Tube Well

http://tns.thenews.com.pk/watering-cost-rice/\#.XUce1vkzbI $\underline{\mathrm{U}}$

\section{Proposed Idea}

The use of Artificial Neural Network (ANN) in multiple fields were vastly implemented and adopted due to its ability to predict the future outcome in which it provide benefits such as reducing production cost thus reducing overall operational cost and also predicting the future outcome when certain inputs were inserted.

With Artificial Neural Network (ANN), it provides further possibilities in which it can learn non-linear pattern which is not available in Machine Learning (ML).

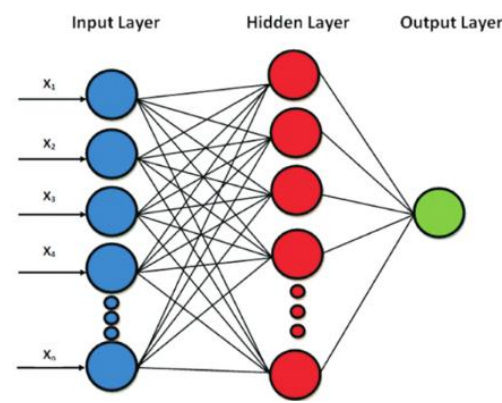

Fig. 10: Artificial Neural Network

https://www.researchgate.net/figure/Structure-of-the-Artific ial-Neural-Network-model_fig2_305432476

Proposed idea would be to compare prediction performed by Recurrent Neural Network (RNN) variant 1) Long Short-Term Memory (LSTM) prediction model with Hargreaves evapotranspiration rate equation with 2) LSTM prediction model with FAO-56 Penman-Monteith (PMF56) evapotranspiration rate equation and 3) LSTM prediction model with Turc evapotranspiration rate equation. Based on literature reviewed, LSTM prediction model provide better prediction than Feed Forward Neural Network (FFNN) and Multivariate Linear Regression (MLR) in terms of its accuracy.

Ahmed (2017) conducted a research on paddy field using Multivariate Linear Regression (MLR) to predict water lost by monitoring surface water level and weather condition using sensors [26]. From the historical data collected, Ahmed created a prediction model using MLR to forecast water demand. He managed to improve water utilization, but a later research done by Tsakiri et al. (2018) found out that MLR is not as advance compared to Artificial Neural Network (ANN) [27]. Tsakiri et al. (2018) had done a research on Flood Prediction using Artificial Neural Network (ANN) and comparing it with Multivariate Linear Regression (MLR)

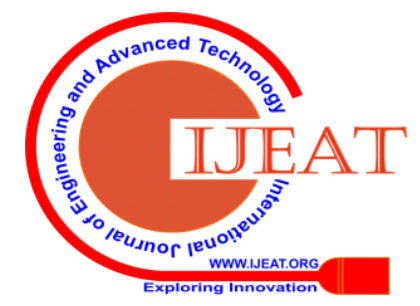


They found out that ANN have better accuracy than MLR in prediction with $96 \%$ prediction accuracy [27]. ANN can provide non-linear relationship between inputs and outputs [27]. Mashaly and Alazba (2016) had done research on comparing the performance of Multi-Layer Perceptron (MLP) also known as Feed Forward Neural Network (FFNN) and Multivariate Linear Regression (MLR) on solar still under hyper-arid environment. They found that FFNN offer better overall performance in precision compared to MLR [28].

A research done by Mustika and Nugrobo (2018) in which they incorporate Artificial Neural Network (ANN) as their prediction model shows that ANN provide a good prediction with 0.1 learning rate [29]. They also mentioned that there was no reason to add more hidden layers because it does not have any impact in accuracy [29]. This was a crucial information as adding more hidden layer may result to more cost on computational resources to train the model thus increasing time needed to train the model.

After further research reviews, it was found that Long Short-Term Memory (LSTM) offer better accuracy than Feed Forward Neural Network (FFNN) and Multivariate Linear Regression (MLR). Adeyemi et al. (2018) in their research on predicting crops water need found that Recurrent Neural Network (RNN) variant LSTM has better performance than FFNN since it has the ability to learn in long-term and in which it can memorize short-term dependency [30]. RNN has one disadvantage which is the vanishing gradient problem which is why LSTM is preferable. As the neural network keeps on learning, training and storing information, the weight keeps on reducing which mean the accuracy will keeps on reducing as the neural network keeps on. Adeyemi et al. (2018) also found out that adding more than one hidden layer will reduce the prediction accuracy for FFNN [30]. They also found out that Neural Network outperform Machine Learning [30].

Adeyemi et al. (2018) did not include the use of any standard equation for calculating evapotranspiration rate which are Penman-Monteith equation or Hargreaves equation. Penman-Monteith equation was developed by United Nations Food and Agriculture Organization (FAO) is also known as FAO-56 Penman-Monteith (PMF56) equation that is used specifically to measure water lost due to evaporation and transpiration. They also lack automation which is made possible with the use of IoT. According to FAO in their "Chapter 2: FAO Penman-Monteith equation", they claimed that PMF56 is the best equation when it comes to evapotranspiration calculation for living grass crops.

As for the calculating evapotranspiration rate (ETo), Djaman et al. (2015) found that PMF56 is the most accurate in estimating water lost since it is a standard equation which was develop specifically by FAO to estimate water lost for grass crop [31]. But due to its requirements, some researchers consider other alternative such as Hargreaves and Turc evapotranspiration rate equation.

It was found out that Hargreaves equation provide better accuracy than PMF56 equation which were supported in researches done by in [32], [33], [34]. Research done by Fernandes et al. (2012) which compare six evapotranspiration rate equations with PMF56 equation found that Hargreaves

were among the nearest to achieve accurate result [35]. However, according to Almorox et al. (2008), Turc equation offer better accuracy than Hargreaves equation but Hargreaves offer simplicity than Turc equation [36].

So, further investigation needs to be done between PMF56, Hargreaves and Turc equations in order to find which equations offer better water lost estimation since there are several factors that may affect the result such as location and data availability in which the results may vary either having small gap or vice versa.

In conclusion, Recurrent Neural Network (RNN) variant, Long Short-Term Memory (LSTM) offer better accuracy compared with Feed Forward Neural Network (FFNN) in Artificial Neural Network (ANN) league. Since LSTM outperform FFNN, and FFNN outperform MLR, it is safe to assume that LSTM outperform MLR. Combining LSTM with Hargreaves equation for better prediction accuracy. Finding the right equation equals to finding better prediction.

A research conducted by Faisal et al. (2018) shows that with the use Internet of Things (IoT) for smart irrigation, the farmers can reduce water usage up to $20 \%$ [37]. IoT for irrigation research were supported by many researchers because it can provide better water utilization due to automatic irrigation.

With the implementation of IoT, farmers can monitor the field because the sensors that collect the data from the field were send to the farmers which provide them with real time update to them without actual going to the field themselves via messaging [38], website [39] and mobile application [40]. With the available data collected through the IoT sensors, it will help the farmers in their decision making to control their irrigation.

This show that the combination of Artificial Neural Network (ANN) with Internet of Things (IoT) can have a significant impact to the overall agricultural process. As for irrigation, with the combination on ANN and IoT, this means that farmers can reduce water usage for their irrigation process which have an overall impact to their operational cost. With ANN and IoT, it can provide an automatic irrigation process based on prediction model developed. From the predicted model, it will provide an overall summary on irrigation prediction in which the farmers can monitor and have a better control their field. This in result will have impact on reduction on human dependency [11], [40], [41], [42]. ANN learn and compare between stored action, in this case is the prediction outcome based on historical data with the current data to predict the appropriate action that can be taken.

Smart agriculture has helped many farmers around the world in their farming activities in way that they managed to optimize the use of their resources and further reducing water and electricity bills and labour services for farming purposes while improving overall yield production. It is said that with the implementation of smart irrigation, water usage can be reduced regardless of any types of crops and plants. 


\section{Smart Irrigation Prediction using Artificial Neural Network (ANN) with Evapotranspiration Rate Equations and Internet of Things (IoT) for Paddy Field}

\section{METHODOLOGY}

\section{A. Research Activities}

1) Preliminary Activities

In this stage, in order to have a solid groundwork, background study need to be done by reviewing related research papers related to the research. The authors divided this research into few categories which are:
a) Irrigation
b) Evapotranspiration Rate
c) Artificial Neural Network
d) Internet of Things
e) Paddy

The authors also had contacted Mr. Mohd Khalid, Research Assistant (RA) form Malaysian Agricultural Research and Development Institute (MARDI) in Parit, Malaysia regarding paddy and paddy field to get better insight and better understanding about paddy in depth. The questions asked were:
a) How was the irrigation been done in Parit?
b) How frequent was the irrigation?
c) Are there any factors to irrigate the field?
d) What paddy variety were grown in the field?

Based on the evapotranspiration rate equations from research papers and information from Mr. Khalid, the authors had listed few important data which are needed for this research. The data are as below:
a) Wind Speed
b) Temperature
c) Solar Radiation
d) Precipitation
e) Humidity
f) Soil Moisture
g) Rainfall

\section{2) Design Development}

a) Evapotranspiration Rate

Currently, there are several evapotranspiration rate equations available to be used apart from standard equation which is FAO-56 Penman-Monteith (PMF56) equation. The equations can be divided into three categories [35], [43]. The first category is based on temperature which consist of Camargo equation, Blaney-Criddle equation and Hargreaves-Samani equation. As for the second category is based on radiation which consist of Turc equation, Makkink equation, Jensen-Haise equation and Priestley-Taylor equation. The last category is based on mass-transfer which Rohwer equation.

Hargreaves equation was in temperature category according to Xu and Singh (2002) [43] and it also can be in radiation category according to Fernandes et al. (2012) [35]. The reason why those equations were more favourable than PMF56 equation was due to their flexibility in calculating the evapotranspiration rate while still having the best near result while having less meteorological data. The reason why all those alternative equations exist was because to accommodate with lack of meteorological data needed by PMF56. With those alternative equations, it will cater with what meteorological data available on the regions as it may not always available on the regions due to several reason such as weather stations were not available on that particular region or the weather station do not have particular set of data set which were required by PMF56. It also can reduce computation time for prediction model development while still having an accurate result even with less meteorological data according to Arif et al. (2012) as cited in [44].

Those equations were developed for that sole purposes to accommodate different use case. The end results showed that Hargreaves equation achieved the nearest accuracy with PMF56 equation as the benchmark of the study while having less meteorological data [35], [43].

\section{b) Artificial Neural Network}

The historical data collected will be used to develop Long Short-Term Memory (LSTM). Based on the reviewed literature, the training and testing ratio can be divided into either 70:30 [29] and 75:25 [30]. Ponraj and Vigneswaran (2019) implemented $60 \%$ for training, 25\% for validating and $15 \%$ for testing [45]. From the ratio data for training and testing, it can affect the prediction model accuracy. If the ratio for training is high, it might suffer for over fitting and if the ratio for testing is high, it might suffer inaccuracy.

In order to achieve one of the best performances in developing prediction model is by setting up the batch size by $2^{\wedge} n$. According to Sato (2017), by using the batch size by $2^{\wedge} n$ equation, it can have the best performance compared to the smaller batch size due to the same iteration number [46]. He also added that by using Nvidia CUDA ${ }^{\circledR}$ Deep Neural Network library (cuDNN), the computing time improved by more than $50 \%$ faster than without using the library on most test done. cuDNN is a GPU-accelerated library that is tuned specifically for developing LSTM prediction model.

The prediction models will be evaluated with Root Mean Squared Error (RMSE), Mean Absolute Error (MAE), Mean Squared Error (MSE) and R-squared $\left(\mathrm{R}^{2}\right)$ to measure their prediction accuracy.

c) Internet of Things (IoT)

IoT will be used as to monitor the field by collecting data through the sensors placed on the field. The data collected were analyzed by the prediction model to control the irrigation based on the output of the model.

\section{B. Preliminary Results}

LSTM was found that to offer better prediction accuracy compared to FFNN and MLR [30]. Hargreaves equation for calculating evapotranspiration rate was found to have less error rate when used compared to FAO-56 Penman-Monteith (PMF56) equation thus having better accuracy [32]. Another research had a different outcome which they found that Turc equation had better accuracy than Hargreaves equation, but Hargreaves equation offers simpler equation than Turc equation [36].

With IoT implementation, it was found that it can reduce water usage up to $20 \%$ [37].

Published By:

Blue Eyes Intelligence Engineering \& Sciences Publication

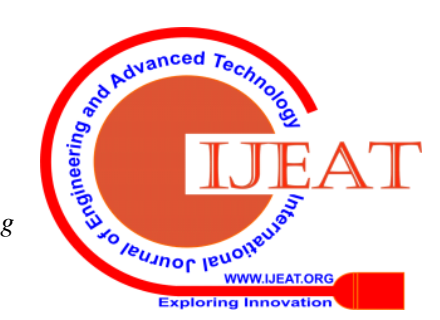


Combination of LSTM with Hargreaves equation and IoT will achieved better water utilization for irrigation.

\section{Architecture Configuration}

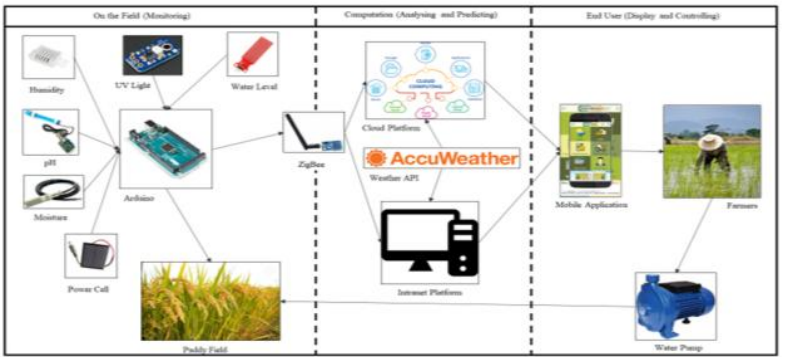

Fig. 11: Conceptual Architecture

\section{Flowchart}

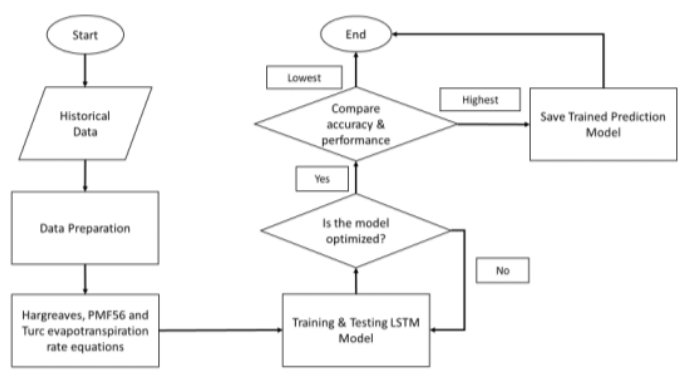

Fig. 12: Algorithm Development

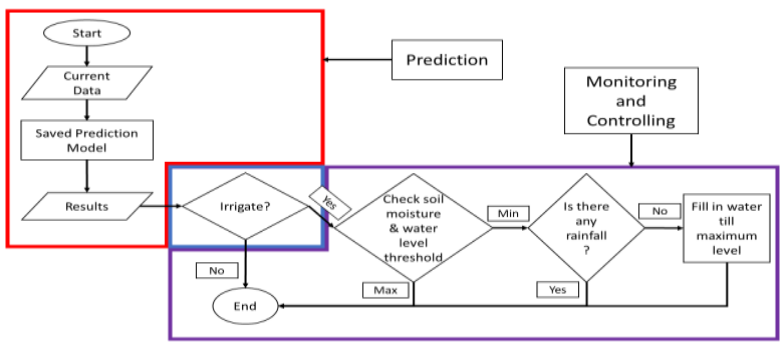

Fig. 13: Algorithm Deployment

\section{RESULT AND DISCUSSION}

The proposed solution in theory, will achieved higher water utilization with the use of Artificial Neural Network (ANN) which is Long Short-Term Memory (LSTM) and Hargreaves evapotranspiration rate for better water lost estimation and better requirement flexibility and with the addition of Internet of Things (IoT) to monitor and control the irrigation automatically according to the output generated by the neural network. As for the result, since this research is an ongoing research, the actual result may change in the future and the proposed solution might be not achieved as the theories suggested on the reviews done.

\section{CONCLUSION}

Smart agriculture is highly recommended research field by researchers and because this sector provides food resources, the way of managing those processes need to be highly efficient and effective. Based on the reviews done for paddy, there are three problems which are quality and quantity, diseases and water management or irrigation. Irrigation is focused because water scarcity will become a major problem in near future as the water demand increases proportionally to and insight on their paddy field. environment in the long run. monthly allowances. research.

\section{REFERENCES} e-data-historical https:/globalagriculturalproductivity.org/ -agriculture . alternative to the current traditional irrigation technique since it can provide future information of irrigation by prediction. With prediction model, farmers will have a better information

Smart irrigation can reduce water usage and provide automatic irrigation based on the prediction model developed. This indirectly reduce human dependency to monitor and to control the irrigation. Farmers can control their irrigation either in manual mode or in automatic mode depending on the predicted summary of the day. With smart irrigation, it can directly improve crops quality and increase crops yield quantity with optimum water usage and it is better for the

The main challenges are to find the right algorithm to achieve better prediction accuracy which need to be tackle.

\section{ACKNOWLEDGMENT}

The authors would like to thank to Germany's government for providing a scholarship for this research for four months in Rheinisch-Westfälische Technische Hochschule Aachen University (RWTH Aachen) under DAAD Scholarship by providing a research placement in KISTERS AG Aachen and

The authors also would like to thank to Professor Dr. Horst Lichter and Dr. Marian Walter from RWTH Aachen University for making this arrangement possible. The authors also would like to thank to Dr. Dirk Schwanenberg, Dr. Frank Schlaeger and Dr. Daniel Otten from KISTERS AG Aachen for providing a research placement in their company and for their valuable feedbacks, opinions and suggestions for this

Lastly, the authors would like to thank Mr. Mohd Khalid Agricultural Research and Development Institute (MARDI) in Parit, Perak, Malaysia for invaluable information regarding paddy and their way of managing the paddy field.

1. Malaysia Climate Data: Historical. (n.d.). Retrieved from https://climateknowledgeportal.worldbank.org/country/malaysia/climat

2. Top 25 Developed and Developing Countries. (2019, August 2) https://www.investopedia.com/updates/top-developing-countries/

3. Castañeda, A., Doan, D., Newhouse, D., Nguyen, M. C., Uematsu, H., \& Azevedo, J. P. (2016). Who are the poor in the developing world? The World Bank. Retrieved from https://elibrary.worldbank.org/doi/abs/10.1596/1813-9450-7844

4. Steensland, A. \& Zeigler, M. (2018, October). 2018 Global Agricultural Productivity Report ${ }^{\circledR} \quad$ (GAP Report ${ }^{\circledR}$ ). Retrieved from

5. Clayton, C. (2018, October 17). Progressive FARMER. Global Food Gap Growing. from https:/www.dtnpf.com/agriculture/web/ag/news/world-policy/article/2 018/10/17/group-warns-food-supply-meet-future-2

6. Water Uses. (2016). Retrieved from http://www.fao.org/nr/water/aquastat/water use

Khokhar, K. (2017, March 22). Chart: Globally, 70\% of Freshwater is Used for Agriculture. Retrieved from http://blogs.worldbank.org/opendata/chart-globally-70-freshwater-used

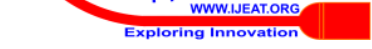




\section{Smart Irrigation Prediction using Artificial Neural Network (ANN) with Evapotranspiration Rate Equations and Internet of Things (IoT) for Paddy Field}

8. Hall, K. (2016, August 30). Forbes. Water For Sustainable Growth: How Biotechnology Crops Are One Solution. Retrieved from https://www.forbes.com/sites/gmoanswers/2016/08/30/gmos-water-bal ance/\#106d08c36975

9. Osman, M. F. (2017) An empirical analysis of Malaysia rice in the world food market industry. Retrieved from http://ir.uitm.edu.my/id/eprint/18893/

10. Types of Agricultural Water Use: Irrigation vs Rain-Fed Agriculture. (2016, October 11). Retrieved from https://www.cdc.gov/healthywater/other/agricultural/types.html

11. Yashaswini, L. S., Vani, H. U., Sinchana, H. N., \& Kumar, N. (2017, September). Smart automated irrigation system with disease prediction. In 2017 IEEE International Conference on Power, Control, Signals and Instrumentation Engineering (ICPCSI) (pp. 422-427). IEEE. Retrieved from https://ieeexplore.ieee.org/document/8392329

12. Competency Area 3: Drainage and Irrigation AEM. (2010). Retrieved from https://nrcca.cals.cornell.edu/soil/CA3/CA0324.php

13. Thierry Facon. (n.d.). WATER MANAGEMENT IN RICE IN ASIA: SOME ISSUES FOR THE FUTURE. Retrieved from http://www.fao.org/3/x6905e/x6905e0g.htm

14. How to manage water? (n.d.). Retrieved from http://www.knowledgebank.irri.org/step-by-step-production/growth/wa ter-management

15. Kaedah Penggunaan Manual Tanaman Padi. (2019, September 10). Retrieved from http://www.iadapp.gov.my/Web/Page/Default.aspx?Page=KaedahTana manPadi-2

16. CHAPTER 2: CROP WATER NEEDS. (n.d.). Retrieved from http://www.fao.org/3/s2022e/s2022e02.htm

17. Rowshon, M. K., Amin, M. S. M., Mojid, M. A., \& Yaji, M. (2014) Estimated evapotranspiration of rice based on pan evaporation as a surrogate to lysimeter measurement. Paddy and water environment, 12(1), 35-41. Retrieved from https://www.researchgate.net/publication/257495334_Estimated_evap otranspiration_of_rice_based_on_pan_evaporation_as_a_surrogate_to _lysimeter_measurement

18. Agriculture's use of water. (n.d.). Retrieved from http://www.fao.org/3/Y3918E/y3918e03.htm\#TopOfPage

19. Bouman, B. (2009). How much water does rice use. Management, 69 115-133. Retrieved from https://www.researchgate.net/profile/Bas_Bouman/publication/281474 989 How_much_water_does_rice_use/links/5a56cfe7aca272bb6963fa c7/How-much-water-does-rice-use.pdf

20. [Goud, V. V. (2015). Rice does not need water. Retrieved from https://www.downtoearth.org.in/coverage/rice-does-not-need-water-10 108

21. Gulati, A., \& Thakur, S. (2018, January). Smart Irrigation Using Internet of Things. In 2018 8th International Conference on Cloud Computing, Data Science \& Engineering (Confluence) (pp. 819-823). IEEE. Retrieved from https://ieeexplore.ieee.org/document/8442928

22. Wikipedia contributors. (2019, September 2). Drip irrigation. In Wikipedia, The Free Encyclopedia. Retrieved 08:51, September 12, 2019,

from https://en.wikipedia.org/w/index.php?title=Drip_irrigation\&oldid=913 607250

23. Madhavan, N. (2013, January 6). Drip irrigation: One drop at a time. Retrieved from https://www.businesstoday.in/magazine/cover-story/drip-irrigation-ofpaddy-improves-yields-saves-water/story/190843.html

24. CHAPTER 7: CHOOSING AN IRRIGATION METHOD. (n.d.). Retrieved from http://www.fao.org/3/S8684E/s8684e08.htm

25. Toriman, M. E., \& Mokhtar, M. (2012). Irrigation: types, sources and problems in Malaysia. In Irrigation systems and practices in challenging environments. IntechOpen. Retrieved from http://cdn.intechopen.com/pdfs/34120/InTech-Irrigation_types_source s_and_problems_in_malaysia.pdf

26. Ahmed, F. (2017, October). An IoT-big data based machine learning technique for forecasting water requirement in irrigation field. In International Conference on Research and Practical Issues of Enterprise Information Systems (pp. 67-77). Springer, Cham. Retrieved from https://link.springer.com/chapter/10.1007/978-3-319-94845-4_7

27. Tsakiri, K., Marsellos, A., \& Kapetanakis, S. (2018). Artificial Neural Network and Multiple Linear Regression for Flood Prediction in Mohawk River, New York. Water, 10(9), 1158. Retrieved from https://www.mdpi.com/2073-4441/10/9/1158/pdf

28. Mashaly, A. F., \& Alazba, A. A. (2016). MLP and MLR models for instantaneous thermal efficiency prediction of solar still under hyper-arid environment. Computers and Electronics in Agriculture,
122 ,

146-155.

Retrieved

from

https://www.sciencedirect.com/science/article/pii/S016816991630003 5

29. Mustika, I. W., \& Nugroho, L. E. (2018, August). Optimized Back-propagation Artificial Neural Network Algorithm for Smart Agriculture Applications. In 2018 4th International Conference on Science and Technology (ICST) (pp. 1-5). IEEE. Retrieved from https://ieeexplore.ieee.org/abstract/document/8528655

30. Adeyemi, O., Grove, I., Peets, S., Domun, Y., \& Norton, T. (2018). Dynamic neural network modelling of soil moisture content for predictive irrigation scheduling. Sensors, 18(10), 3408. Retrieved from https://www.mdpi.com/1424-8220/18/10/3408

31. Djaman, K., Balde, A. B., Sow, A., Muller, B., Irmak, S., N'Diaye, M. K., ... \& Saito, K. (2015). Evaluation of sixteen reference evapotranspiration methods under sahelian conditions in the Senegal River Valley. Journal of Hydrology: regional studies, 3, 139-159. Retrieved

from https://www.sciencedirect.com/science/article/pii/S221458181500006 3

32. Subathra, M. S. P., Blessing, C. J., George, S. T., Thomas, A., Raj, A. D., \& Ewards, V. (2019). Automated Intelligent Wireless Drip Irrigation Using ANN Techniques. In Advances in Big Data and Cloud Computing (pp. 555-568). Springer, Singapore. Retrieved from https://link.springer.com/chapter/10.1007/978-981-13-1882-5_49

33. Bogawski, P., \& Bednorz, E. (2014, September 12). Comparison and validation of selected evapotranspiration models for conditions in Poland (Central Europe). Water Resources Management, 28(14), 5021-5038. Retrieved

https://link.springer.com/article/10.1007/s11269-014-0787-8

34. Arif, C., Mizoguchi, M., \& Setiawan, B. I. (2013). Estimation of soil moisture in paddy field using artificial neural networks. arXiv preprint arXiv:1303.1868. Retrieved from https://arxiv.org/abs/1303.1868

35. Fernandes, L. C., Filho, O. C. R., \& Paiva, C. M. (2012). Evaluation of six empirical reference crop evapotranspiration equation. Case study: Campos dos Goytacazes. Revista Brasileira de Meteorologia, 27(3). Retrieved from http://www.scielo.br/pdf/rbmet/v27n3/a02v27n3.pdf

36. Almorox, J., Hontoria, C., \& Benito, M. (2008). Comparación de algunos métodos de estimación de la evapotranspiración en Uruguay. Revista Ingeniería Química, 33, 5-9. Retrieved from https://www.researchgate.net/publication/280830934_COMPARACIO N_DE_ALGUNOS_METODOS_DE_ESTIMACION_DE_LA_EVAP OTRANSPIRACION_EN_URUGUAY

37. Faisal, R. H., Saha, C., Hasan, M. H., \& Kundu, P. K. (2018, December). Power Efficient Distant Controlled Smart Irrigation System for AMAN and BORO Rice. In 2018 21st International Conference of Computer and Information Technology (ICCIT) (pp. 1-5). IEEE. Retrieved from https://ieeexplore.ieee.org/document/8631927

38. Nawandar, N. K., \& Satpute, V. R. (2019). IoT based low cost and intelligent module for smart irrigation system. Computers and Electronics in Agriculture, 162, 979-990. Retrieved from https://www.sciencedirect.com/science/article/pii/S016816991831807 6

39. Singh, P., \& Saikia, S. (2016, December). Arduino-based smart irrigation using water flow sensor, soil moisture sensor, temperature sensor and ESP8266 WiFi module. In 2016 IEEE Region 10 Humanitarian Technology Conference (R10-HTC) (pp. 1-4). IEEE. Retrieved from https://ieeexplore.ieee.org/document/7906792

40. Kumar, A., Surendra, A., Mohan, H., Valliappan, K. M., \& Kirthika, N. (2017, July). Internet of things based smart irrigation using regression algorithm. In 2017 International Conference on Intelligent Computing, Instrumentation and Control Technologies (ICICICT) (pp. 1652-1657) IEEE. Retrieved

https://ieeexplore.ieee.org/abstract/document/8342819

41. Huong, T. T., Thanh, N. H., Van, N. T., Dat, N. T., Van Long, N., \& Marshall, A. (2018, July). Water and Energy-Efficient Irrigation based on Markov Decision Model for Precision Agriculture. In 2018 IEEE Seventh International Conference on Communications and Electronics (ICCE) (pp. 51-56). IEEE. Retrieved from https://ieeexplore.ieee.org/document/8465723

42. Jha, K., Doshi, A., Patel, P., \& Shah, M. (2019). A comprehensive review on automation in agriculture using artificial intelligence. Artificial Intelligence in Agriculture. Retrieved from https://www.sciencedirect.com/science/article/pii/S258972171930018 2

Published By:

Blue Eyes Intelligence Engineering \& Sciences Publication

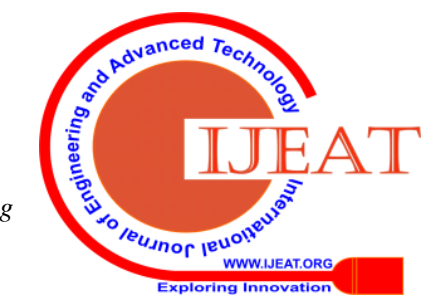


43. Xu, C. Y., \& Singh, V. P. (2002). Cross comparison of empirical equations for calculating potential evapotranspiration with data from Switzerland. Water Resources Management, 16(3), 197-219. Retrieved from http://folk.uio.no/chongyux/papers_SCI/WARM_8.pdf

44. Jha, K., Doshi, A., Patel, P., (2018). Intelligent Irrigation System using Artificial Intelligence and Machine Learning: A Comprehensive Review. Retrieved from https://www.researchgate.net/publication/329098253_INTELLIGENT _IRRIGATION_SYSTEM_USING_ARTIFICIAL_INTELLIGENCE_ AND MACHINE_LEARNING_A_COMPREHENSIVE_REVIEW

45. Ponraj, A. S., \& Vigneswaran, T. (2019). Daily evapotranspiration prediction using gradient boost regression model for irrigation planning. The Journal of Supercomputing, 1-13. Retrieved from https://link.springer.com/article/10.1007/s11227-019-02965-9

46. Sato, M. (2017, March 15). Performance comparison of LSTM with and without cuDNN(v5) in Chainer. Retrieved from https://chainer.org/general/2017/03/15/Performance-of-LSTM-UsingCuDNN-v5.html

\section{AUTHORS PROFILE}

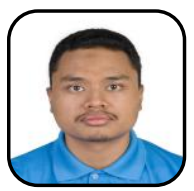

Muhammad Zahid bin Hilmi, is a Master by Research student under Computer Information and Science (CIS) department in Universiti Technologi PETRONAS. He graduated from Universiti Teknologi PETRONAS for his bachelor's degree in information technology (Hons.) majoring in Cloud Computing in January 2019. He continued his study for MSc in March 2019 and his research area are on agriculture, artificial intelligence, connected and embedded system.

As of February 2020, he is currently continuing his research in UTP after finishing his research attachment in Germany from August 2019 December 2019.

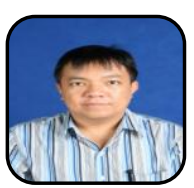

Associate Professor Dr. Toni Anwar, graduated from RWTH Aachen University, Germany as Dr. rer. nat. in Mobile Communications and studied International Management at TU Berlin, Germany. He is an Associate Professor Dr. at Universiti Teknologi PETRONAS and worked for multinational companies (Ericsson Sweden, Motorola USA, Siemens Germany etc.) for more than 10 (ten) years and in academic world for more than 15 (fifteen) years in different countries such as Germany, Thailand, Malaysia and Indonesia.

$\mathrm{He}$ is an IEEE Senior Member and also MBOT professional member as Professional Technologies. His research areas are Software Engineering, Embedded System/IoT, Smart Agriculture, Smart Cities, Artificial Intelligence, Data Analytics, Location Based Services, Augmented Reality, Connected Healthcare and ICT. His research grants include international grants from Europe, Japan, Thailand, Malaysia, Indonesia from industry, academic and government related organizations.

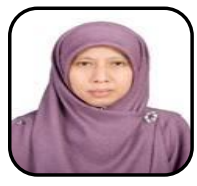

Assosiate Professor Dr. Dayang Rohaya Awang Rambli, is an Associate Professor in the Department of Computer and Information Sciences, Universiti Teknologi PETRONAS (UTP), Malaysia. She received her PhD degree (Computer Science) from Loughborough University in 2005. Her MSc degree (Computer Science) and BSc (Computer Science) were obtained from Western Michigan University in 1987 and University of Nebraska, Omaha, USA in 1985 respectively. Currently, she is a researcher at the Institute of Health Analytics (UTP), leading the Visualization \& Interaction Research group. Her research interest lies in the area of virtual reality, augmented reality and human computer interaction focusing on visualization and human factors issues in the field of healthcare, education \& training.

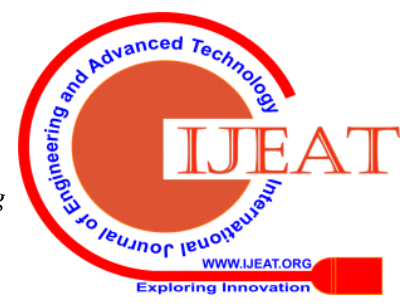

